ojs.uv.es/index.php/qdfed

Rebut: 02.06.2020. Acceptat: 29.06.2020

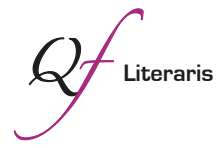

Per a citar aquest article: Ritondale, Elena. 2020. "El relato de la migración contemporánea desde la perspectiva de la crítica como sabotaje: tres casos de estudio". Quaderns de Filologia: Estudis Literaris XXV: $39-55$.

doi: $10.7203 /$ qdfed.25.I8980

\title{
El relato de la migración contemporánea desde la perspectiva de la crítica como sabotaje: tres casos de estudio
}

The contemporary migration narration from the perspective of criticism as sabotage: three case studies

\author{
Elena Ritondale \\ Universitat Autònoma de Barcelona \\ elenaritondale@gmail.com
}

Resumen: El texto que se propone se enfoca en un análisis crítico de tres relatos sobre la migración centroamericana, a través de la herramienta teórica propuesta por Manuel Asensi, la "crítica como sabotaje". En particular, estudia tres crónicas -Los migrantes que no importan. En el camino con los centroamericanos indocumentados en México (Martínez, 2010), Los niños perdidos. Un ensayo en cuarenta preguntas (Luiselli, 20I6) y Yo tuve un sueño. El viaje de los niños centroamericanos a Estados Unidos (Villalobos, 20I8)-. El análisis se centra en elementos como: el narrador, su posicionamiento; la presencia de silogismos explícitos o encubiertos; la propuesta de "modelos de mundo" procedentes de cuestiones directa o indirectamente vinculadas con el tema general de la migración.

Palabras clave: migración; crónicas; fronteras; crítica; sabotaje.

Abstract: This text focuses on a critical analysis of three stories on Central American migration, through the theoretical tool proposed by Manuel Asensi, "criticism as sabotage". In particular, it studies three chronicles -Los migrantes que no importan. En el camino con los centroamericanos indocumentados en México (Martínez, 20Io), Los niños perdidos. Un ensayo en cuarenta preguntas (Luiselli, 20I6) y Yo tuve un sueño. El viaje de los niños centroamericanos a Estados Unidos (Villalobos, 20I8)-. The analysis will focus on elements such as: the narrator, his positioning; the presence of explicit or hidden syllogisms; the proposal of "world models" arising from issues directly or indirectly linked to the general theme of migration.

Keywords: migration; chronicle; borders; critics; sabotage. 


\section{Preguntas, objetivos y bases de este trabajo}

La migración es un tema que, en los últimos 20-30 años, ha tenido un lugar central en los estudios académicos. Por otro lado, también se han publicado obras de ficción, poesía y crónica -sin querer ser exhaustiva y limitándome solo al contexto hispanoamericano ${ }^{\mathrm{I}}$ destaco entre sus autores a Luis Humberto Crosthwaite (2002), Oscar Martínez (2010), Valeria Luiselli (2016 y 20I9), Javier Zamora (20I7), Claudia Hernández (20I8), Balam Rodrigo (20I8), Juan Pablo Villalobos (20I8)-. En el presente estudio analizo Los migrantes que no importan (2010) ${ }^{2}$, de Óscar Martínez; Los niños perdidos (2016), de Valeria Luiselli y Yo tuve un sueño (20I8), de Juan Pablo Villalobos, desde la perspectiva de la crítica como sabotaje de Manuel Asensi (20II), y también haciendo referencia a su teoría de los modelos de mundo (2007, 20II, 20I6).

La primera hipótesis que propongo es que las obras de Luiselli, Martínez y Villalobos llevan a cabo una crítica del modelo de Estado cuya herramienta fundamental es la frontera. Esta, como dispositivo de control biopolítico, forma parte del contexto en el que se producen "relaciones asimétricas, conflictivas y violentas", y donde se presentan "con mayor intensidad procesos conjuntivos, disyuntivos e inyuntivos" en palabras de Manuel Valenzuela (2014: ıо). Así, en las páginas que siguen se quiere averiguar cómo (y hasta qué punto) los tres autores sabotean discursos hegemónicos y proponen modelos de mundo "otros".

Al respecto, cabe puntualizar algunas cuestiones. En primer lugar, siguiendo la distinción propuesta por Manuel Asensi entre textos téticos y atéticos33, hay que aclarar que todas las obras propuestas tienen una tesis específica y la función que quieren desempeñar es, a su vez, modelizadora; pueden ocultar, además, ideologías y mensajes "secundarios" o "paralelos", mientras hacen

\footnotetext{
${ }^{\mathrm{I}}$ En otro trabajo (en prensa), co-editado con Tania Pleitez, enfocado en la migración infantil y juvenil, hemos trazado un mapa de la difusión de estos relatos, haciendo hincapié en cómo, en general, las obras escritas desde Centroamérica han recibido menor difusión y visibilidad frente a las publicadas en México o en Estados Unidos.

${ }^{2}$ El autor primero escribió sus crónicas para el periódico El Faro, de El Salvador.

${ }^{3}$ Retomando una idea ya presentada en su trabajo de 2007, Asensi explica que "los textos téticos [son aquellos cuya] estrategia fundamental es la de ocultar su carácter entimemático o sus fisuras", mientras que los textos atéticos "en su disposición dan a ver su composición silogística y ponen en crisis la posibilidad de esta composición" (20II: 53). Aunque afirme que los primeros requieren un sabotaje por parte de la crítica y que los segundos, en cambio, solo necesitan que la crítica describa su acto de sabotaje, Asensi aclara que la composición silogística se da tanto en unos como en otros.
} 
explícita su tesis fundamental. Esto sería el caso del ensayo de Valeria Luiselli, que hace explícita su tesis sobre los niños migrantes mientras que, tal vez, encubre en parte sus ideas sobre la maternidad o sus finalidades autoficcionales, tal como se ha propuesto en el trabajo ya referido (en prensa).

La investigación que ha llevado a la escritura del presente artículo empezó, así, con una pregunta: ¿cabe estudiar las obras de algunos de los mayores autores que se han dedicado a escribir sobre las fronteras latinoamericanas como textos que actúan a partir de modelos de mundo y que, tal como propone Asensi, a través de silogismos realizan una acción modelizadora hacia los lectores? O, en cambio, ¿resulta más útil estudiar su acción de sabotaje de discursos hegemónicos que, a lo largo de siglos y más aún en los años de la globalización, han ido imponiendo un modelo de mundo basado en la idea de Estados que se tienen que defender de los "otros" con drones, muros, leyes especiales que ponen en escena en las fronteras de las naciones más ricas un estado de excepción permanente? Tal duda/dificultad se ha fortalecido frente a la constatación de que, por lo menos algunos de estos autores -me refiero a Luiselli y Villalobos- han sido reconocidos por el mercado y han sido traducidos en varios idiomas. ¿No sería entonces su obra, también, hegemónica, por lo menos en el mundo cultural, debido, además, a la idea de que incluso los discursos que entran en competencia con las narraciones hegemónicas acaban viendo esta competencia "generalmente neutralizada dentro de los sistemas capitalistas por el devenir mercancía de todos los objetos en circulación” (Asensi, 20II: I7)?

Dos han sido los elementos que me han llevado a optar por la segunda perspectiva propuesta -esto es, estudiar su acción saboteadora de discursos hegemónicos sobre el Estado-nación y las fronteras-: el posicionamiento de la crítica como sabotaje con respecto a los subalternos y el concepto de polisistema, teorizado por Itamar Even-Zohar y retomado por Asensi. Ya en un texto de 2007, Asensi escribía que

"la crítica como sabotaje" adopta el punto de vista operativo de un grupo heterogéneo: el de los subalternos o vencidos. Y no se trata de hablar por ellos, ni de representarles, sino de adoptar su punto de vista heterogéneo, plural, lo cual debe hacerse en medio de la vigilancia y de la auto reflexividad más estrictas (I48; cursiva del original).

En el texto de 20II Asensi vuelve a destacar las "Políticas de la crítica como sabotaje" (77), recordando que esta, siguiendo la línea indicada por Horkheimer, "aspira a instaurar una situación más justa entre los hombres", apuntando 
a la "organización total del edificio social" (Horkheimer en Asensi, 20Ir: 77). Así, la crítica como sabotaje asume una función ético-política específica. Dejando de momento al lado la fundamental cuestión indicada por Asensi de la diferencia entre "hablar por" y "adoptar un punto de vista", solo se recuerda que el autor indica cómo

adoptar el punto de vista del subalterno es una idea y un acto complejo por cuanto no se entiende aquí la subalternidad como una posición fija y esencial (20II: 80).

Tal afirmación permitirá acercarse al análisis de la representación de la condición migrante a partir de la idea de que no se trata de un sujeto homogéneo, que se puede encasillar en definiciones y estereotipos unitarios. En cambio, se trata de una condición que comparten sujetos acomunados por experiencias parecidas, pero muy heterogéneos en cuanto a edad, género, condiciones diferentes. Así, para aclarar mi posicionamiento con respecto a los textos que se estudian a continuación, asumiendo la idea de que "[l]a crítica como sabotaje es [...] móvil en lo que a su punto de vista se refiere", recuerdo que "dicha movilidad tiende a volverse estática cuando elige aquellos puntos de vista de los que aparecen como definitivamente desahuciados" (80).

El segundo elemento que me ha llevado a elegir la perspectiva que he adoptado ha sido el concepto de polisistema. Siguiendo a Itamar Even-Zohar, este es

un sistema múltiple, un sistema de varios sistemas con intersecciones y superposiciones mutuas, que usa diferentes opciones concurrentes, pero que funciona como un único todo estructurado, cuyos miembros son interdependientes (1990: 3).

Y si, de acuerdo con Asensi, la literatura es "un sistema más del polisistema modelizante" (2007: 138), esto me lleva a proponer que, aunque pueda darse el caso de textos literarios que han tenido cierto éxito en el mundo editorial, el contexto en el que se mueven no deja de ser un polisistema, donde su posición relevante en el marco del "sistema editorial" podría ser marginal si se considera el polisistema en su conjunto. Dicho de otra forma, y siguiendo la propuesta de Even-Zohar, dentro del polisistema se dan tensiones y conflictos entre discursos diferentes y, a veces, antagónicos. Una autora con éxito editorial, de hecho, puede acabar no incidiendo absolutamente en los modelos de mundo hegemónicos (político, de la información, de las instituciones) que diseñan una idea de nación, de seguridad, de "nosotros" y "los demás". 
Por lo tanto, esto me ha permitido estudiar los textos propuestos considerándolos saboteadores de un modelo de mundo hegemónico. Claramente, no dejaré de hacer hincapié en los posibles silogismos encubiertos que indiquen contradicciones y posicionamientos ambiguos por parte de estos autores con respectos a temas específicos. Antes de ahondar en algunos conceptos teóricos que me parece importante definir, sin embargo, presento otras hipótesis de este trabajo. Además de cuestionar el modelo de mundo cuyo símbolo y herramienta principal es la frontera, propongo que estos autores cuestionan la integridad del Estado-nación o, mejor dicho, su identificarse con una "homogeneidad" de su población.

Otro objetivo es tomar en consideración el problema de la voz: en estas obras, ¿quién es el sujeto de la narración? ¿Cuánto espacio dejan los autores a los adolescentes y niños migrantes? ¿Hasta qué punto logran no hacer de ellos solo un recurso más para fortalecer su posición autorial en ese (poli) sistema cultural?

En primer lugar, como adelanté, me referiré a la teoría de Manuel Asensi sobre los modelos de mundo (20II y 20I6).

En su trabajo más reciente, Asensi escribe que:

[T]odo discurso [...] presenta un modelo de mundo que posee una capacidad modelizadora, la cual lleva a los sujetos a realizar acciones y a representarse a sí mismos de un modo determinado. [...] De hecho, una de las claves de la expresión 'modelo de mundo' recae en el valor de modelización que contiene, de ahí que se hable de las acciones a las que son llevados los sujetos (2016: 40).

Así, la acción modelizadora es, de acuerdo con su propuesta, la que determina a los sujetos -tanto sus discursos y sus prácticas, como sus cuerpos-, de tal forma que, debido a esta acción performativa de los modelos, dichos sujetos conciben el mundo y a sí mismos según modelos que se han codificado previamente. Tales modelos, a su vez, representan parte de una política normativa cuyo objetivo principal es autoacreditarse, justamente a través de la presentación de estos modelos como "naturales".

Sin embargo, estamos de acuerdo con Nuria Calafell, quien observa cómo

todo sujeto que se quiera crítico debe, antes que nada, analizar cómo estas discursividades hegemónicas construyen modelos de mundo que vienen a añadirse, a confirmar o a desmentir los modelos de mundo de los/as receptores/ as (2014: 460). 
La herramienta retórica fundamental que permite la transición del modelo de mundo representado por los discursos al receptor es el silogismo. Este, en palabras de Nuria Calafell,

implica aceptar como parte inseparable e integrante del discurso literario un componente afectivo, por medio del cual el texto literario es capaz de proporcionar un filtro perceptivo-ideológico del mundo que apoye o rechace el modelo perceptivo-ideológico de los/as receptores/as (20I4: 462).

Asensi, a partir de estas premisas y como síntesis de sus propuestas anteriores, define la crítica como

el ejercicio de aquellas máquinas textuales lineales o no lineales [...] que presentan una composición silogística entimemática como algo natural, transparente o mimética. O bien, la práctica de una cartografía de aquellos textos que funcionan como un sabotaje de un determinado modelo de mundo (20II: 53).

En este sentido, el trabajo que presento es un inicio de cartografía (como tal, parcial), de los textos que, en los últimos 20 años, en Hispanoamérica, han cuestionado la Frontera -en particular, entre México y EE. UU., pero también la frontera sur mexicana-y los discursos que la defienden.

\section{La frontera como discurso falaz}

Las tres obras propuestas de Martínez, Luiselli y Villalobos presentan diferencias importantes, pero todas llevan al lector a cuestionar la legitimidad de la frontera, no solo exponiendo los efectos que los dispositivos de control fronterizos tienen sobre la población migrante, sino postulando nuevas formas de ciudadanía. Este elemento se hace visible sobre todo en los textos de Luiselli y Villalobos, a través del planteamiento de la posibilidad de un hogar fuera del hogar, de una nación fuera del Estado-nación, de comunidades que identifican su patria con un territorio que no coincide únicamente con un idioma, con la idea de "homogeneidad".

Martínez describe las vicisitudes de los migrantes sobre todo en su paso por México, desde una narración personal; el narrador acompaña a muchos migrantes en el camino y se vuelve así uno de los personajes, su relato toma posición abiertamente y no oculta sus sentimientos y emociones. Luiselli, en cambio, nos informa sobre la odisea de los niños y jóvenes en los Estados Unidos para obtener el permiso de quedarse en el país como refugiados; el 
tono de la voz de la narradora en su obra parece más neutro, aunque no deja de ser visible su posicionamiento. El elemento tal vez más interesante de su ensayo es el protagonismo que los niños adquieren, aún más si se tiene en cuenta que su presencia ocupa espacios tradicionalmente dedicados a los adultos (tribunales, fiscalías, etc.). Luiselli se incluye en el marco de los migrantes, pero como si fuera un "primus inter pares": aunque haya tenido que luchar por una green card, es consciente de que sus condiciones económicas y familiares le han brindado la posibilidad de una migración mucho menos precaria. Lo que se tendría que desarrollar -y que se deja para otro estudio, por razones de espacio- es la presencia de un elemento autoficcional importante en su texto que, a partir del subtítulo, pretendería ser solo un ensayo. Villalobos parece borrar su presencia de la narración (menos en el epílogo) y deja que los testimonios de los migrantes se entreguen en primera persona. Claramente, su autoría se reconoce en la selección de las partes de los relatos que él ha considerado más relevantes; en la connotación dada a cada una de estas, en la elección del orden en que presentar las historias y en el título que las anticipa. Sin embargo, según él mismo admitió 4 , su intención fue la de ocupar el menor espacio posible. Esto se hace visible en particular en la historia de una chica hondureña, titulada "El sol de acá". Villalobos ha contado cómo esta historia le afectó de forma particular, por tratarse de un testimonio de violación masiva, y de sus consecuencias. Como forma de respeto hacia las palabras de esa migrante, su relato apenas parece haber sido editado por el autor. La fragmentariedad y el desorden del discurso de la chica dejan intacto su trauma, él no trata de imponerle un orden externo y ajeno.

En las páginas que siguen me enfocaré, como adelanté en la introducción, en cómo los tres autores sabotean los discursos que legitiman la existencia de las fronteras.

Siguiendo a Foucault (2005), asumimos que la soberanía -a partir de la Modernidad- se ha impuesto a través del control de los cuerpos, de sus vidas, de sus funciones y de la posibilidad de regularlas y organizarlas. Ahora bien, las fronteras en la Modernidad desempeñan un papel de control biopolítico regulando el acceso al territorio y conllevando, además, según el ya mencionado Valenzuela, una gama de normas, reglas, dinámicas de control y exclusión

\footnotetext{
${ }^{4}$ Durante la clase-conferencia en el curso de Literatura Hispánica de la profesora Dunia Gras, Universidad de Barcelona, el día I9 de mayo de 2020 .
} 
específicas5. Según Giorgio Agamben (2006), además, es también en los contextos asociados con la migración y el control de las fronteras donde se produce un "estado de excepción".

De acuerdo con tal estado de excepción, se asume que en ciertos contextos se puede suspender el orden jurídico y que, por ejemplo, algunas garantías y derechos quedan interrumpidos. Propongo que la detención de migrantes (y, en particular, de los menores) se puede leer en este marco, lo que nos recuerda las palabras de Benjamin, en su octava tesis de filosofía de la historia, sobre el hecho de que el estado de excepción se ha vuelto la regla para los oprimidos.

La acción ejercida por discursos hegemónicos de la que habla Asensi es entonces, también, la que, a lo largo de los siglos, ha llevado a justificar la supuesta necesidad de este estado de excepción; además, ha modelado un tipo especial de subjetividad: los que Foucault definiría como los cuerpos dóciles (2005).

En Los niños perdidos, Luiselli sabotea el discurso sobre las normas fronterizas iluminando la falta de sentido y de utilidad y hasta lo ridículo de una de las herramientas empleadas por parte del gobierno de EE. UU. para seleccionar a los menores que tienen derecho a entrar y a los que no lo tienen. Las "cuarenta preguntas" que estructuran su ensayo son las que la autora -como traductora en los juicios contra estos niños- tiene que dirigirles para averiguar si realmente corren algún riesgo en su país de origen. Los niños, algunos de ellos muy pequeños, no entienden las preguntas o no saben contestar.

¿Por qué viniste a Estados Unidos?

Eso no sé.

¿Cómo viajaste hasta aquí?

Nos trajo un señor.

¿Un coyote?

No, un señor.

Okey. ¿Y el señor se portó bien con ustedes?

Sí se portaba bien, yo creo.

¿Y por dónde cruzaron la frontera?

Eso no sé.

¿Texas? ¿Arizona?

Sí, Texas Arizona (Luiselli, 2016: 52).

\footnotetext{
${ }^{5}$ En el caso de los territorios fronterizos mexicanos, además, y de otros contextos poscoloniales, este poder adquiere más bien características que han sido estudiadas en el marco de la necropolítica (Mbembe, 20II; Valencia, 20I0, entre otros). Sin embargo, no se ahondará esta línea teórica aquí.
} 
No solo se hace hincapié en la falta de sentido del cuestionario, sino que se ilumina la perspectiva adultocéntrica desde la que se ha diseñado. Pero el espacio público que leemos en el ensayo de Luiselli está repleto de niños que lo han puesto en "crisis"6; junto con estos niños encontramos a las mujeres. No todos los traductores que trabajan en las cortes son mujeres, pero en el relato de Luiselli parece leerse una presencia mayor de ellas en las ONG, en los servicios de asistencias a los migrantes que piden entrar a ser parte de una nueva ciudadanía. Niños y mujeres son, justamente, los sujetos que, en la Modernidad, han sido encerrados en los espacios privados, de acuerdo con un modelo de mundo dominante.

También Óscar Martínez se enfoca en el sinsentido de la legislación que impide el tránsito libre de los migrantes, en el capítulo de su crónica titulado "La Bestia":

Viajar en tren como polizón es indignante. Allá arriba se te ocurren decenas de preguntas absurdas: ¿por qué vamos colgados del techo si los vagones viajan vacíos? (2010: 64)

Tanto Luiselli, como Villalobos y Martínez, además, sabotean el discurso securitario que sustenta las políticas migratorias de Estados Unidos (pero de todos los Estados que pretenden cerrar sus fronteras, incluido México y sus políticas sobre la frontera sur). Una de las formas en que lo hacen es deconstruir el silogismo: en Centroamérica hay pandillas -los pandilleros son violentos- los centroamericanos son violentos.

Luiselli cuestiona este silogismo dedicando mucho espacio a Manu, un adolescente de Tegucigalpa que ha tenido que huir de su país porque una pandilla quería reclutarlo y él se negaba a hacerlo. Después de haber asistido al asesinato de su mejor amigo, de haber ido a la policía para denunciar a los

\footnotetext{
${ }^{6}$ Se destaca una diferencia bastante importante en el uso de la palabra "crisis" por parte de Luiselli y de Villalobos. El autor problematiza el concepto y, al hacerlo, parece realizar una acción de sabotaje del discurso hegemónico sobre la migración (que, como dijimos, busca justificaciones para mantener un "estado de excepción" al respecto). De hecho, haciendo hincapié en las razones estructurales de la migración la define como "la supuesta crisis migratoria", mientras que Luiselli parece emplearla de una forma más neutral y sin problematizarla. Neutraliza un término que no lo es. Villalobos, además, sabotea la forma en la que se ha narrado esta crisis, siempre determinada, en los discursos hegemónicos, por el desplazamiento de unos hacia el lugar de los otros. En cambio, en el epílogo, Villalobos pregunta: “¿Dónde está la crisis entonces? ¿En el lugar que recibe o en el que expulsa? ¿En las decisiones de quienes la nombran en sus relatos y la sitúan de un lado u otro de esta o aquella frontera?” (20I8: s/p). De la crónica de Villalobos se ha consultado el e-book.
} 
asesinos y de haber quedado completamente desprotegido, no le queda otra opción que huir de esa violencia. Sin embargo, al llegar a Nueva York y al entrar en una escuela de un barrio de la ciudad, Manu descubre que también ahí hay las bandas, que le vuelven a presionar para que entre en una de ellas. La narradora nos entrega las palabras desesperadas de Manu: "Hempstead es un hoyo de mierda lleno de pandilleros, igual que Tegucigalpa" (20I6: 74).

Compartiendo el mismo acercamiento, pero ahondando mucho más en la verdad histórica sobre el nacimiento de las pandillas, Villalobos realiza el mismo cuestionamiento del silogismo según el cual la política securitaria sería necesaria para que Estados Unidos pueda dejar afuera los violentos y, así, "protegerse" como cuerpo social. Con palabras claras recuerda la responsabilidad de Estados Unidos en el surgimiento de la violencia de las pandillas en el Triángulo del Norte. El autor destaca cómo las bandas nacieron en los años sesenta en Los Ángeles, y que se trata de un "producto de transformación y exportación estadounidense hacia América Central” (20I8: s/p). Luego, explica:

[f]ue en los años noventa, durante la administración de Bill Clinton, que alguien tuvo la idea de deportar a esos criminales a lugares que no estaban preparados para asimilarlos [...]. Comenzaron a llegar a Tegucigalpa, San Salvador y Guatemala unos jóvenes solos, sin familia ni, muchas veces, vínculos sociales con los países que habían abandonado cuando niños. Que hablaban inglés. Estaban conectados. Traían rutinas, necesidades, experiencia en el crimen (s/p).

En general, la estrategia adoptada por los tres autores es deconstruir el elemento en el que se funda el silogismo al que ya hice referencia: la generalización, la construcción de identidades desacreditadas a priori. El estigma colectivo, de hecho, afecta a los migrantes centroamericanos, pero, en particular, a los jóvenes, y resulta ser una de las causas del que se ha definido como juvenicidio (Valenzuela, 20I2, 20I2b, 20I5). La forma más simple y efectiva por la que apuestan los tres autores es, por lo tanto, acotar su enfoque. Relatan la historia de sujetos, no de categorías; devuelven profundidad a cada vicisitud humana, problematizan, matizan, se detienen en las contradicciones de sus historias. Así es como lo hace Martínez, relatando la historia de Pitbull, uno de los tres hermanos que acompaña durante una parte de su trayecto en México:

-A ver, pinche marerito, a mi país vienes a hacer tus fechorías. Te vamos a recomendar tres años para que aprendas a no venir a joder.

La apariencia no le ayudó. Pitbull tiene ese caminar insolente de los pandilleros, que doblan las rodillas y aflojan el cuerpo para balancearlo de lado a lado. 
El pelo al ras, y una mirada retadora que sale de su rostro redondo y que siempre ve de reojo, hacia arriba, como si estuviera a punto de atacar.

Ni siquiera intentó explicar al policía que no era ningún marerito, sino solo un joven de Centroamérica (2010: 30).

Otros recursos narrativos empleados por los tres autores para sabotear ese modelo de mundo que apoya discursos en favor de fronteras "fuertes" son el desplazamiento del enfoque narrativo y, como consecuencia, una subversión de la representación de víctimas y victimarios.

Con respecto al primer tema, los tres escritores adoptan de alguna forma el punto de vista de los migrantes, aunque en medidas diferentes. Luiselli, debido a su condición de clase -que no niega- es tal vez la que lo hace con más cuidado. Aunque ella también ha migrado, y por hablar sobre todo de niños y adolescentes, no escribe desde su posición, pero relata su punto de vista. Martínez y Villalobos, en cambio, llevan a cabo este desplazamiento de forma más evidente: Martínez lo hace a nivel práctico, ya que -aunque no sea migrantepara escribir sus crónicas realiza el trayecto con ellos y conoce en el campo las dificultades que han vivido. Villalobos, en cambio, porque renuncia a entrar como narrador en su crónica y escribe desde la perspectiva y la voz narradora de los migrantes. Si el elemento estructurante en el texto de Luiselli son las preguntas del cuestionario del Tribunal, en la crónica de Villalobos se trata de las frases de los protagonistas; así, los títulos de los diferentes capítulos son algunas de sus palabras, las que más afectaron al autor.

Como se ha adelantado, este desplazamiento permite resituar conceptos como el miedo y el peligro. Las herramientas de defensa del Estado-nación se vuelven así, claramente, herramientas de ofensa. Estos aliens-migrantes no son representados como cuerpos que ofenden, sino como cuerpos ofendidos y vulnerados por las medidas de seguridad y por los que tienen que vigilar para que se respeten.

Villalobos subvierte los argumentos en favor de la frontera en distintos momentos de la narración; sin embargo, a través del suspense, hay un punto de la crónica en que logra hacerlo de forma muy contundente. En "La cabuya", dos primas adolescentes y la hija de 8 meses de una de ellas han llegado al río que marca el límite entre México y Estados Unidos. Tienen que cruzarlo, junto con las otras personas que forman parte de su grupo. La corriente es muy fuerte y alguien empieza a gritar. La prima que lleva a la niña entre sus brazos sabe que no podrá sobrevivir cruzando el río en esas condiciones. Entonces, un desconocido se ofrece para llevar a la niña, ayudado por otros dos hombres que lo agarrarían en el cruce. Hay desconfianza; ese desconocido puede ser 
un coyote que, harto del llanto de la niña y con miedo a que pueda atraer la atención de la Migra, decida deshacerse de ella. Las mujeres no tienen otra opción, y aceptan su ayuda:

Seguimos caminando, el agua a las rodillas, en los muslos, en la barriga. Pronto ya no tocamos el fondo. El río nos empuja con fuerza, queriendo arrastrarnos, enojado. El frío nos entume las piernas, los brazos, cuesta trabajo mantener la respiración. A veces trago un poco de agua, pero no me suelto de la cabuya. — iNo se suelten de la cabuya! -grita una persona- jagárrense bien fuerte!

Unos empiezan a llorar. Otros gritan que no pueden, que se los va a llevar el río. Estamos en medio y ya no se puede ver la orilla. Pero yo miro para atrás y a la luz de la luna veo a la niña en lo alto, los brazos fuertes del hombre que la protege, la niña que atraviesa la frontera encima del agua (20I8: s/p).

Se trata de una imagen lírica y tierna: las siluetas del hombre y la niña iluminadas por la luz de la luna. El modelo de mundo basado en una división entre lo que es legal/bien e ilegal/mal aquí se sabotea gracias a varios elementos. Quiero, sin embargo, enfocarme en el suspense. Este se crea a partir del momento en que el lector empieza a temer por la suerte de la niña, que podría acabar siendo arrastrada por el río o, quizás, abandonada por el hombre. Entre los migrantes, se sabe, hay muchos coyotes, muchos traficantes de hombres que estarían dispuestos a cualquier cosa para hacer más rápido el cruce. Y no. El hombre no la abandona. Ambos violan esa frontera que nadie querría, en este momento, que siguiera invulnerable7. Violar la frontera y salvar la vida de la niña, en este punto, van de la mano. Esto acontece porque la idea del "nosotros", aquí, logra desplazarse, volverse una elección del lector y no un asunto legal (nosotros/los que respetamos las leyes vs los migrantes/ los ilegales) o un destino que depende de un vínculo entre sangre y suelo.

Parte de la deconstrucción de la retórica de la seguridad nacional pasa por un replanteamiento de los conceptos de víctima y victimario. La "necesidad" de las fronteras nacionales se basa en el presupuesto de que estas tendrían que defender las comunidades de los peligros que pueden llegar desde el exterior: dejar afuera la violencia, la guerra, la muerte. Martínez, por su parte, destaca exactamente los peligros que dentro de un estado (en el caso de su crónica, México), encuentran los migrantes que huyen de sus países:

\footnotetext{
7 Destaco que este suspense y la actitud que genera en el lector no cambiaría si se tratara de ficción, o si, unas páginas más adelante, se descubriera que la niña y su madre han muerto.
} 
Uno de ellos ya volvió a El Salvador en una bolsa negra. Los hermanos Alfaro decidirán esta noche qué hacer. Tienen que decidir con tino; si no, podrían encontrar aquí lo que buscan dejar allá abajo (20I0: 25).

Otro elemento relevante realizado por el periodista es el cuestionamiento del papel de los que tendrían que garantizar la seguridad y la protección de las fronteras. Estos sujetos que tendrían que encarnar la imagen de la seguridad nacional hacen que el viaje de los "ilegales" llegue a ser, indudablemente, más difícil. Pero ¿cómo? Los policías violan, forman bandas de secuestradores de migrantes. De representantes del orden, en la mayoría de los testimonios y las narraciones sobre los migrantes centroamericanos, se vuelven símbolos del caos y la violencia. Refiriéndose a los tres hermanos migrantes Alfaros, Martínez reflexiona:

Queda claro que en cuanto a migrar se trata, los tres son inexpertos. Escapar es otra cosa, no hay alternativa ni mucha estrategia. Solo aquella que la prisa permita. En este camino hay lobos y caperucitas. Ellos no se mueven como lobos" (2010: 42).

También Luiselli y Villalobos iluminan esta responsabilidad, en distintos niveles, de los agentes de seguridad. Luiselli hace hincapié en una "violencia de la ley", la que, con procedimientos urgentes, drones y códigos impide la llegada de los migrantes o los repatria. Villalobos, por su parte, destaca más explícitamente cómo los defensores de los confines nacionales (los cuerpos de policía) a menudo reciben dinero de esos mismos traficantes y narcos cuyo paso la frontera tendría que parar, supuestamente. Muchos testimonios en sus páginas coinciden en este intercambio de dinero entre criminales, miembros de pandillas y policías.

Habría muchos otros elementos que destacar en este trabajo de deconstrucción de modelos de mundo por parte de los tres autores. Por ejemplo, se podría ahondar en cómo se sitúan con respecto a subjetividades que son representadas a menudo con lenguajes que las basurizan, victimizan, racializan; de qué forma logran realizar una estética de la ruptura, basada en elementos semánticos y formales que remiten a las heridas, las comunidades rotas, las narraciones múltiples y parciales de los migrantes, para construir un relato colectivo de estos sujetos subalternos y heterogéneos, en palabras de Asensi (20II). Por razones de espacio, no me detengo en todos estos aspectos, aunque sean fundamentales. 
Solo comparto algunas reflexiones que han sido objeto de otro trabajo (Ritondale, en prensa), para indicar de qué forma contribuyen a esta deconstrucción de modelo de mundo nacionalista que se rige en las fronteras. Me refiero en particular a la que he definido como una estética de la ruptura y que he hallado en la mayoría de los autores que han representado al viaje de los migrantes. En el pasado he interpretado la presencia de cuerpos mutilados, macheteados o cortados por la Bestia como una metonimia de la ruptura de las comunidades y de las familias, apoyándome en estudios anteriores sobre la presencia de imágenes de cuerpos rotos en las narrativas sobre el narco, que también remite a una lectura de este tipo (Fuentes, 20I3; Ritondale, 20I6). Estas imágenes están presentes en los tres textos analizados y abundan, en particular, en la crónica de Martínez donde, por ejemplo, se lee:

mujeres violadas frente a sus familias, hombres mutilados por el filo de machetes, cuerpos rebanados, gente que huye de la muerte que su lugar natal les ofrece, policías delincuentes, violadores, asesinos, gente que viaja en techos de trenes vacíos. Heridas, llagas, secuelas, cadáveres (I7).

El texto de Martínez nos pone frente a lo abyecto, a ese tipo de "escándalo" que se produce cuando la muerte sitia el territorio de la vida y llega a mezclarse con ella (Kristeva, I989). Al respecto, elige la palabra "podredumbre" para describir el viaje (I8). Sin embargo, aunque es cierto que su texto es el que más produce imágenes que pueden -hasta- correr el riesgo de deshumanizar a los migrantes, relatando situaciones que remiten a subjetividades que, desde nuestros lugares "limpios" y "seguros", percibimos como "otras", y que "nos" dan miedo, también es cierto que la estética de su narración tiene una función política. Explica bien cómo esta abyección se produce justamente por la responsabilidad de Estados Unidos, que ha delegado el control de la migración a México, para que estos horrores queden lo más lejos posibles de sus pulcras fronteras: como Italia ha hecho con Libia, como Europa ha hecho con Turquía -esto lo añado yo-. El horror de estos cuerpos rotos (Cavarero, 2009) se hace visible en ellos, pero es el producto de políticas de otros, se debe a otros, que los están victimizando.

En el caso de las obras de Luiselli, Martínez y Villalobos, además, las cicatrices consecuencias del desplazamiento no quedan solo en los cuerpos de los migrantes, sino también en sus relatos, en los discursos que se fragmentan, cuyos particulares en parte se olvidan, que se repiten. Sin embargo, estos fragmentos llegan a ser los ladrillos con los que se construye la contranarrativa, en el caso de Villalobos de forma más evidente. 
Para concluir, solo recuerdo que una de las hipótesis de este trabajo es la de que los relatos sobre los migrantes centroamericanos y mexicanos no solo deconstruyen la lógica securitaria, sino que proponen, de hecho, otro modelo de ciudadanía y de comunidad. Valeria Luiselli lo hace a partir de la herramienta de la traducción, esto es, apostando por un Estado multilingüe; además, deconstruye el protagonismo del hombre (varón) adulto en el espacio público y presenta, como personajes principales de esta odisea posmoderna, a mujeres y niños, sujetos que habían sido relegados durante mucho tiempo al espacio privado.

Villalobos, por su parte, hace de la frontera el objeto de otro discurso. "Yo tuve un sueño", que da título al libro, es la frase pronunciada por una de las migrantes (y no una "cualquiera"). Se trata de la historia más cruda recogida por el autor, la de la joven víctima de la violación múltiple, de la que ya se ha hablado. Es, también, claramente, la frase pronunciada por Martin Luther King. Así, cuando la chica dice:

Yo tuve un sueño. Yo soñé que estaba defendiendo personas. Yo era defensoras de derechos humanos. Yo varias veces he soñado con eso (Villalobos, 20I8: $\mathrm{s} / \mathrm{p})$.

Nos está hablando del sueño americano. No del oficial, por supuesto, vinculado en nuestros días con la retórica del éxito individualista y capitalista, la del America first. Se trata del sueño americano que ha sido objeto de una reivindicación por parte de los movimientos para los derechos civiles que no sabemos si algún día se realizará -y hoy como nunca, con la muerte de George Floyd, lo dudamos-. El sueño de esta chica hondureña llega a ser, así, el símbolo de la nueva Frontera; no la que abría paso al west, no la que cierra el paso de sur a norte, sino la que abre este paso, de sur a norte, y construye una nueva idea de nación. Un nuevo mito, heterogéneo, fragmentario, mestizo.

\section{Bibliografía}

Agamben, Giorgio. 2006. Homo sacer. El poder soberano y la nuda vida. Valencia: Pre-textos.

Asensi, Manuel. 2007. Crítica, sabotaje y subalternidad. Lectora, I3: I33-I53.

Asensi, Manuel. 20Ir. Crítica y sabotaje. Barcelona: Anthropos.

Asensi, Manuel. 20i6. Teorías de los modelos de mundo y de los mundos posibles. Actio nova. Revista de la teoría de la literatura y literatura comparada o: 38-55. 
Calafell, Núria. 20I4. La crítica como sabotaje frente al discurso literario. Kamchatka 4: $457-476$.

Crosthwaite, Luis Humberto. 2002. Instrucciones para cruzar la frontera. México D. F.: Editorial Joaquín Mortíz.

Even-Zohar, Itamar. I990. Polysystem Theory. Traducción de Ricardo Bermudez Otero. Poetics Today II: 9-26.

Foucault, Michel. [I979] 2005. Vigilar y castigar. Madrid: Siglo XXI de España editores.

Fuentes, Felipe Oliver. 20I3. Apuntes para una poética de la narcoliteratura. Guanajuato, Universidad de Guanajuato.

Hernández, Claudia. 2oI8. El verbo j. Bogotá: Laguna Libros.

Kristeva, Julia. I989. Poderes de la perversión. México D. F., Siglo XXI Editores.

Luiselli, Valeria. 20I6. Los niños perdidos. Un ensayo en cuarenta preguntas. Sexto Piso.

Luiselli, Valeria. 20ı9. Desierto sonoro. Madrid: Sexto Piso.

Mbembe, Achille. 2006. Necropolítica. Seguido de Sobre el gobierno privado indirecto. Barcelona: Melusina

Martínez, Óscar. 2010. Los migrantes que no importan. En el camino con los centroamericanos indocumentados en México. Barcelona: Icaria.

Pleitez, Tania \& Ritondale, Elena. En prensa. Introducción en ¿Herida o abrigo? Infancia, juventud y frontera en las literaturas contemporáneas publicadas en México, Centroamérica y Estados Unidos (I990-2019). Istmo. Revista virtual de estudios literarios y culturales centroamericanos 42.

Ritondale, Elena. En prensa. Adolescentes y perspectiva de género en el estado de excepción. La literatura sobre los migrantes como pedagogía. En Zabalgoitia, Mauricio; Ritondale, Elena \& Vallejo Grande, Erick. C. Pedagogías alternativas. Lecciones y transgresiones de la escritura del género en México (s. XX Y XXI). México, IiSUE - UNAM.

Ritondale, Elena. 2oI6. Cuerpo social y cuerpo individual: canibalismo y territorio en Al otro lado de Heriberto Yépez. Mitologías hoy. Revista de pensamiento, crítica Y estudios literarios latinoamericanos I4: 213-232.

Rodrigo, Balam. 20I8. El libro centroamericano de los muertos. México: Fondo de Cultura Económica. E-Book, Google Books. https://play.google.com/books/ reader?id $=\mathrm{O}_{4 x j \mathrm{DwAAQBAJ}}$

Valenzuela Arce, Manuel (coord.). 20I2. Sed de mal. Feminicidios, jóvenes y exclusión social. Tijuana: El Colegio de la Frontera Norte.

Valenzuela Arce, Manuel. 20I2b. Las maras. Identidades juveniles al límite. Tijuana: El Colegio de la Frontera Norte.

Valenzuela Arce, Manuel. 20I4. Transfronteras. Fronteras del mundo y procesos culturales. Tijuana: El Colegio de la Frontera Norte.

Valenzuela Arce, Manuel (coord.). 20I5. Juvenicidio. Ayotzinapa y las vidas precarias en América Latina y España. Barcelona: Ned Ediciones; Tijuana: El Colegio de la Frontera Norte; Guadalajara: ITESO. 
Villalobos, Juan Pablo. 20ı8. Yo tuve un sueño. El viaje de los niños centroamericanos a Estados Unidos. Barcelona: Anagrama. E-book, Google Books. https://play. google.com/books/reader?id=UAtlDwAAQBAJ\&pg=GBS.PPI

Zamora, Javier. 20I7. Unaccompanied. Copper Canyon Press. E-book, Google Books. https://play.google.com/books/reader?id=Kd9XDwAAQBAJ\&pg=GBS. PTI.w.o.o.o.I 
